\title{
AS RELACÕES INTERCULTURAIS NO ENSINO E APRENDIZAGEM DE PORTUGUÊS COMO LÍNGUA ESTRANGEIRA (PLE)
}

\author{
INTERCULTURE RELATIONS ON THE TEACHING AND THE LEARNING OF \\ PORTUGUESE AS A FOREING LANGUAGE (PLE)
}

\author{
Alessandra Montera Rotta \\ Universidade Federal de Uberlândia \\ Lucas Araujo Chagas \\ Universidade Federal de Uberlândia
}

\begin{abstract}
RESUMO: O presente artigo visa discutir as relações interculturais no ensino e aprendizagem do Português como Língua Estrangeira (PLE) em contexto de imersão. Partindo da premissa de que o ensino em contextos étnicos variados, multilíngues e pluriculturais abarca uma heterogeneidade cultural implícita, torna-se primordial o trabalho de abolição das distâncias entre os alunos estrangeiros e o plano cultural, linguístico e social, da Língua Portuguesa. Os professores devem atentar para essa urgência e reconhecer que a sala de aula de PLE torna-se o espaço e o canal de abertura que traz as condições necessárias para o desenvolvimento progressivo da língua e da cultura brasileira.
\end{abstract}

PALAVRAS-CHAVE: ensino e aprendizagem de PLE; intercultural; pluralidade cultural; integração social.

ABSTRACT: This article aims to discuss the intercultural relations on the teaching and the learning of Portuguese as a Foreign Language (PLE) in a context of language immersion. Based on the principle that the teaching in a context of ethnical, multilingual and multicultural variety covers an implicit cultural heterogeneity, it is necessary a treat of distance abolition between foreign students and the cultural, social and linguistic aspects of the Brazilian Portuguese Language. Teachers should attempt to the urgency to recognize that a Portuguese teaching ambient becomes space and channel of sociocultural and language transference, which provides necessary conditions for a good teaching and learning progress.

KEYWORDS: Portuguese Teaching in a context of immersion; intercultural; multicultural variety; social integration.

\section{Introdução}

A questão do intercultural no ensino de línguas está situada entre uma série de conceitos que mantém entre si relações complexas (Gee, 2004; Lankshear \& Knobel, 2003; Cope \& Kalantzis, 2000). Cultura, identidade e etnia fazem parte dessa complexa problemática. Esses três conceitos trazem ao ensino e aprendizagem do Português Como 


\section{Revista do SELL \\ v. $4, n^{\circ} .1$ \\ ISSN: $1983-3873$}

Língua Estrangeira (PLE) ${ }^{1}$ notável contribuição, pois permitem uma reflexão sobre a diversidade de culturas e sobre a problemática dessas diferenças.

Indivíduos e grupos sociais são suscetíveis à adaptação e à evolução. Portanto, as culturas das quais eles se originam também assumem noções dinâmicas que não devem ser reduzidas a definições estáticas do senso comum (Augé, 1992; Balandier, 1974), tais como pensar em cultura apenas como os modos de vida, valores, hábitos e costumes de um povo, cujas manifestações se observam nas diversas formas de comportamento, arte e linguagens. Essa é apenas uma das muitas definições de cultura² ${ }^{2}$

$\mathrm{Na}$ realidade, o termo cultura é bastante vasto e atravessa várias áreas do conhecimento. O conceito antropológico de cultura em Lévi-Strauss (1993), segundo o qual existe progresso quando uma cultura entra em contato com outra (ou outras) cultura(s), traz reflexões importantes para o ensino e aprendizagem de PLE. Partindo desse pressuposto, as trocas culturais que se sucedem servem como mecanismo de propulsão para o progresso: "Jamais as sociedades humanas estão sós; quando parecem mais separadas, ainda o é sob formas de grupos ou feixes" (LÉVI-STRAUSS, 1993, p. 323).

Em situação de pluralidade cultural, essas trocas culturais operam um conhecimento de elementos significativos que o indivíduo imerso em aprendizagem de PLE vai selecionar e utilizar informações culturais segundo seus interesses e as diferenças culturais envolvidas na situação de ensino e aprendizagem. A cultura, tanto quanto a língua, coloca o aluno diante de si e dos outros no mesmo contexto de aprendizagem. No entanto, o mais importante não é descrever as culturas em contato umas com as outras, mas analisar o que se passa dentro do grupo entre os indivíduos que se dizem pertencer a diferentes culturas (ABDALLAH-PRETECEILLE, 2005).

Essa reflexão é o ponto central desse artigo, que visa tratar o conceito de interculturalidade no ensino e aprendizagem de PLE levando em conta as questões acima apontadas.

\footnotetext{
${ }^{1}$ Utilizaremos a sigla PLE para nos referirmos ao Ensino de Português para Estrangeiros (PE) em contextos de imersão.

2 Não é nossa intenção abranger as variadas definições do termo cultura. Concentramo-nos naquela de Lévi-Strauss, por nos parecer mais pertinente à realidade de sala de aula de PLE (Nota dos autores).
} 


\section{Revista do SELL}

v. $4, n^{\circ} .1$

ISSN: $1983-3873$

\section{Perspectivas do intercultural no ensino e aprendizagem de PLE}

Inicialmente designada pela escola francesa como "compétence pluriculturelle" (Sheils, 1998) $^{3}$, atualmente encontramos os termos Competência Intercultural (Cl) e Competência de Comunicação Intercultural (CCI) ao se falar de uma perspectiva orientada para o enfoque comunicativo intercultural, cujos estudos e pressupostos são predominantemente culturais e identitários.

A questão da identidade e da diversidade cultural é apresentada por Candelier (2000 e 2001) como a possibilidade de o indivíduo obter uma participação mais segura nos momentos comunicativos em que a diversidade de línguas e culturas está presente. Vários são os fatores, de acordo com o autor, que interferem nessa interação: a consciência das línguas e da comunicação; a confiança em si mesmo; atitudes positivas perante as línguas, a diversidade, a comunicação e o outro; a disponibilidade para partilhar conhecimentos e experiências; aptidões linguísticas e comunicativas (percepção, escuta, conhecimentos dos sistemas linguístico, semântico e pragmático) e a competência de aprendizagem (curiosidade, o desejo de aprender, e a capacidade de observação e análise).

De fato, uma análise mais aprofundada das relações entre identidade e cultura na em sala de aula de PLE do Curso de Português para Estrangeiros oferecido pela Universidade Federal de Uberlândia (UFU) de 2009-2012 revela que aqueles aprendizes mais aptos às interações culturais, mais abertos ao contato com a cultura do outro, passam a reconhecer o outro e a si mesmos em novos caminhos de aprendizagem. Essa abertura a novas formas de aprendizado parece estar associada ao reconhecimento da diversidade e da singularidade de cada um no grupo, de forma que o professor passa a ser aquele que promove o contato de uns com os outros, encorajando-os a pensar nessa pluralidade cultural não como diferença, mas sim como universalidade em todas as culturas.

Assim, ao se perceber como falante nativo de sua própria língua e como falante de outra língua (L2), o aprendiz compreende que é um ser cultural e que sua cultura se

\footnotetext{
${ }^{3}$ Esta designação surge no entendimento da competência pluricultural como "derivée de la notion de plurilinguisme, elle-même derivée de celle de bilinguisme". SHEILS, J. (coord.) "Apprentissage et usage des langues dans le cadre européen". In: Le Français dans le Monde, Recherches et Applications, 1998. Resumo disponível em http://www.fdlm.org/fle/ra/0798-ra.php. Acesso em 10 de julho de 2013.
} 


\section{Revista do SELL \\ v. $4, n^{\circ} .1$ \\ ISSN: $1983-3873$}

diferencia das demais. O reconhecimento da multiculturalidade leva o aprendiz à constatação da diversidade de raízes culturais que fazem parte do contexto da sala de aula (Candau, 2000; 2002; Forquin, 1993). Ao mesmo tempo, no entanto, é capaz de ampliar seu conhecimento acerca da própria cultura, das demais culturas, da diversidade e da fusão linguística e cultural características do universo que o rodeia. Percebe ainda, e principalmente, que é capaz de se comunicar, e passa a se relacionar com esse universo intercultural de forma dinâmica e socializada. É o que Coste (2004) designou por "approche globale d'une éducation plurilingue" ${ }^{4}$, na linha da definição de competência plurilingue que preside as políticas linguísticas europeias, entendida como: "capacidade para utilizar as línguas para comunicar na interação cultural, na qual o indivíduo, na sua qualidade de ator social, possui proficiência em várias línguas, bem como experiência de várias culturas"(TRIM et al, 2001, p.187).

Chen \& Starosta (1996) definem a Competência Intercultural $(\mathrm{Cl})^{5}$ em três dimensões: 1) a dimensão afetiva, relacionada à sensibilidade intercultural (estão inclusos aqui o conceito que o aprendiz tem de si mesmo, sua abertura ao outro, a atitude de não julgamento, a descontração perante o outro); 2) a dimensão cognitiva, relacionada à consciência intercultural, engloba a consciência de si mesmo e a consciência cultural; e 3) a dimensão comportamental, englobando a competência de comunicação, as habilidades de uso dos códigos verbais e não verbais, o equilíbrio na exposição de si mesmo, a flexibilidade de comportamento, a gestão da interação e as habilidades sociais (empatia e manutenção da identidade).

Essas dimensões nos auxiliam a compreender que o aprendiz de PLE não é apenas produto sua própria cultura, mas que ele a constrói e a elabora em função de estratégias diversificadas, segundo suas necessidades e as circunstâncias de uso no contexto interativo da pluralidade linguística em que se encontra. Suas escolhas culturais serão feitas, portanto, tanto a partir da expressão de sua própria identidade cultural quanto do empréstimo de modelos de comportamento, hábitos e valores da cultura brasileira na qual está inserido.

\footnotetext{
${ }^{4}$ Método global de uma educação plurilíngue (Tradução livre dos autores).

5 "La Compétence Interculturelle $(\mathrm{Cl})$ est la capacité de négocier des significations culturelles et d'accomplir de façon adéquate des comportements de communication efficaces qui reconnaissent les différentes identités des interactants dans un environnement spécifique". CHEN \& STAROSTA, 1996:358-359. In: OGAY, T. De la compétence à la dynamique interculturelles. Bern: Peter Lang, 2000, p. 41-42.
} 


\section{Revista do SELL}

v. $4, n^{\circ} .1$

ISSN: $1983-3873$

\section{A rede de interações no ensino e aprendizagem de PLE}

O conceito de interação nos parece, portanto, central para a definição da cultura e da identidade cultural. De acordo com Goffman (1974), a interação é um sistema sobre o qual se funda a cultura. Sob esse aspecto, a atenção está voltada sobre as relações culturais dinâmicas entre os aprendizes em sala de aula de PLE que dão sentido à comunicação, e não sobre suas culturas: "é a alteridade que precede a relação, e não o inverso" (ABDALLAH-PRETECEILLE, 1999, p.56).

Temos observado em nossas práticas que as diferenças culturais correspondem às relações entre os aprendizes no grupo. Se existe uma relação positiva, de abertura, de contato facilitado nas relações com o outro, a aprendizagem se intensifica e se consolida na aquisição da língua portuguesa. Ao contrário, se as relações são negativas e conflituosas, elas não devem ser justificadas apenas na relação de pertencimento cultural, mas principalmente na dificuldade do professor de estabelecer um ambiente interativo favorável à aprendizagem. Como podemos nos comunicar se não conhecemos o outro? Assim, é fundamental que se estabeleça entre os aprendizes trocas que thes permitam dizer algo, expressar o que pensam e o que sentem em relação à língua e a nova cultura em contexto de aprendizagem.

Trata-se, portanto, de encontrar um equilíbrio entre o que é de domínio universal, referindo-se ao comum a todos os indivíduos em suas línguas e culturas, e o que é de âmbito singular, particular, único nas relações de interação. Através desse equilíbrio, a troca de experiências pessoais, impressões e discussões entre os aprendizes passam a ser o foco do processo de aprendizagem, e o ensino deixa de ser algo descritivo para atingir um patamar de expressão da identidade individual no coletivo.

De acordo com Barbirato (2005), "nesse processo de buscar interagir, o aprendiz pode desenvolver suas habilidades linguísticas de maneira mais profunda e duradoura, uma vez que ele se encontra engajado num processo de construção (e des-construção) de significados" (BARBIRATO, 2005, p.30).

Encontrar um estrangeiro, de qualquer nacionalidade ou cultura, é reconhecer nele uma pessoa não "estrangeira/estranha" a nós, mas como alguém cuja uma das muitas características que apresenta é a nacionalidade estrangeira. Se as diferenças culturais pressupõem um julgamento, elas também se inscrevem na singularidade de cada um, e 


\section{Revista do SELL \\ v. $4, n^{\circ} .1$ \\ ISSN: $1983-3873$}

podem ser aprendidas - e melhor aceitas - nas dinâmicas de interação intercultural proporcionadas pelo professor em sala de aula de PLE .

\section{O paradigma intercultural: o papel do professor de PLE}

A aprendizagem de línguas (L2 e LE) deve estar pautada em contextos interacionais em que alunos e professores colaborem conjuntamente na construção de significados sobre um determinado conhecimento. Contextos que permitam aos alunos construir novos significados, organizar e o controlar seu próprio aprendizado das relações de interação em sala de aula de línguas estrangeiras.

A ênfase na interação parte do princípio da troca de palavras entre ao menos dois interlocutores (aluno/aluno/professor). Examinando mais atentamente 0 padrão interacional na sala de aula podemos compreender, portanto, como se dá a construção do conhecimento. Moita Lopes (1996) tem se dedicado aos estudos sobre a interação com ênfase ora no professor, ora no aluno, ora em ambos, o que nos permite obter uma ideia bastante clara dos estados interativos desenvolvidos pelos aprendizes envolvidos nesse processo durante a aprendizagem.

Transferindo essa reflexão para a questão do intercultural, vemos que ele está na fronteira entre o saber e o agir. Nesse sentido, sabendo que ele se apoia em diferentes dimensões, conforme já descritas no item anterior, é importante salientar que ele também deve se basear na reflexão sobre a ação do professor, a fim de se obter uma prática docente de pesquisa científica. Ao se constatar que o intercultural coloca o aprendiz no lugar do indivíduo que produz cultura por si mesmo na interação com outras culturas, estabelecendo aí relações identitárias, as estratégias de aprendizagem de PLE devem ser desenvolvidas levando-se em conta essa percepção.

No plano metodológico, essas estratégias devem estar ligadas a um trabalho sobre a compreensão da cultura do outro. Se o intercultural pressupõe a situação de diversidade cultural, é necessário que a ação do professor induza os aprendizes a questionamentos sobre as culturas presentes no grupo e focalize sua prática na pluralidade cultural como processo de interação, de reciprocidade, de experiências interpessoais, de construção de novos significados nas produções de alteridade. 


\title{
Revista do SELL
}

v. $4, n^{\circ} .1$

ISSN: $1983-3873$

Mas como podemos conciliar o respeito à diversidade cultural e a necessidade de reconhecimento daquilo que é universal? De acordo com Abdallah-Preteceille \& Porcher (1998), deve haver uma ética da diversidade, em que a liberdade e o respeito à complexidade cultural são estabelecidos na relação entre os sujeitos e não no sujeito. Dessa maneira, a diversidade cultural conduz o aprendiz a agir sem que ele perca sua própria identidade cultural.

O desenvolvimento de atividades em sala de aula de PLE deve ser pautado, pois, na comunicação e na discussão em grupo. O Quadro Europeu Comum de Referência para o ensino de línguas (2001) referenda nossa afirmação:

\begin{abstract}
A abordagem plurilinguística ultrapassa esta perspectiva e acentua o fato de que, à medida que a experiência pessoal de um indivíduo no seu contexto cultural se expande da língua falada em casa para a da sociedade em geral e, depois, para as línguas de outros povos (aprendidas na escola, na universidade ou por experiência direta), essas línguas e culturas não ficam armazenadas em compartimentos mentais rigorosamente separados; pelo contrário, constrói-se uma competência comunicativa, para a qual contribuem todo o conhecimento e toda a experiência das línguas e na qual as línguas se inter-relacionam e interagem. (QCER, 2001, p. 23)
\end{abstract}

Para que esse trabalho se efetive, o professor precisa estar atento tanto à metodologia quanto a essa experiência de diversidade cultural e alteridade, passando da pragmática à aprendizagem de PLE ligada a valores humanistas, já apregoados pelo Conselho da desde a década de 90 . Se o plurilinguismo é desenvolvido pelo professor, a experiência cultural será ainda maior e mais rica (BYRAM, 1992).

\section{Uma experiência intercultural no ensino e aprendizagem de PLE: o Projeto Brasil Sem Fronteiras ${ }^{6}$}

O Projeto Brasil sem Fronteiras foi criado em 2012 pelos professores do curso PLE da Universidade Federal de Uberlândia (UFU) com o objetivo abrir espaço para que os estudantes do curso tivessem oportunidade - através de uma prática de ensino

\footnotetext{
${ }^{6}$ Projeto de extensão ligado ao ensino e aprendizagem de PLE na Universidade Federal de Uberlândia (UFU).
} 


\section{Revista do SELL}

v. $4, n^{\circ} .1$

ISSN: $1983-3873$

transcultural - de vivenciar e compreender as diferentes linguagens, códigos e significados intrínsecos à Cultura Brasileira e à Língua Portuguesa a partir de uma perspectiva real e não apenas estudantil.

Esperava-se, além de favorecer o ensino e aprendizagem de PLE, que não apenas os alunos do curso fossem beneficiados, mas que a sociedade na qual eles estavam imersos tivesse a oportunidade de refletir sobre suas praxes sociais e diferentes movimentos e aspectos de sua cultura, de forma a repensá-la pelo olhar do outro (LOCK, 1978). Acreditava-se, também, na possibilidade de conscientizar essa comunidade sobre o aumento de estrangeiros de várias partes do mundo que têm chegado na região para trabalhar, estudar ou mesmo acompanhar suas famílias.

Como ponto de partida, pensou-se em firmar parcerias com organizações não governamentais (ONG's) da região, que desenvolvessem trabalhos voltados para a progressão cultural e valorização cidadã das comunidades locais com perspectivas glocais (Pennycook, 2004). Queríamos levar nossos alunos para cidades menores, menos globais que Uberlândia (MG) que fizessem parte da região administrativa do Triângulo Mineiro e Alto Paranaíba, já que a região possui traços culturais particulares em relação ao restante do Estado de Minas Gerais. Gostaríamos que eles tivessem a oportunidade de vivenciar práticas sociais familiares, trabalhistas e organizacionais brasileiras e não apenas práticas sociais voltadas para a vida universitária, a qual é bastante parecida comparada às de suas culturas.

Após algumas tentativas de parcerias, o Lions Clube de Patrocínio (MG) abriu suas portas para que realizássemos o projeto em suas dependências. À equipe do Lions, ficou a responsabilidade de organizar uma pequena conferência de abertura; um café cultural com pratos típicos da região; um momento em que cada estrangeiro participante do projeto falaria sobre o seu país e as relações destes com o Brasil (momento que chamamos de Espaço Mundo Brasil); passeios culturais em museus, fazendas, rios, e/ou elementos que marcavam as características sócio-organizacionais daquela cidade (momento que chamamos de Espaço Brasil sem Fronteiras); e por fim oferecer um domingo em família aos estrangeiros participantes do projeto.

À equipe de professores e coordenadores do curso de PLE da UFU, coube o trabalho de organizar e gerir a viagem e expor, nas aulas de português, curiosidades históricas, geográficas e culturais da cidade de Patrocínio e da região. Além disso, falava- 


\section{Revista do SELL \\ v. $4, n^{\circ} .1$ \\ ISSN: $1983-3873$}

se na forma brasileira de se preparar para uma viagem e em particular nas ligações de Uberlândia com a cidade de destino.

Como fruto desse intercâmbio cultural esperava-se, além de promover a interculturalidade, a construção de novos saberes e principalmente de ideais humanos abertos ao diferente, tanto por parte do imigrante, quanto por parte do hospedeiro e como produto dessas relações o fortalecimento de ambas as identidades, criando assim espaços interculturais sem preconceitos, sem violência étnica e de propagação de ideais humanitários.

Durante a realização do projeto, notamos em particular do começo ao fim o deslumbramento dos estrangeiros em relação ao diferente. Em particular a desconstrução de crenças construídas em um primeiro momento sobre o comportamento linguístico e social do primeiro contato com o Brasil que se deu em Uberlândia.

No discurso de muitos deles era notável o desejo de enunciar o que estavam vivenciando, ainda que com alguma dificuldade linguística. Destacavam-se também seus olhares deslumbrantes em relação à natureza rica e diversificada do Cerrado Mineiro:

"É incrível pensar que há menos de $140 \mathrm{~km}$ de Uberlândia existe uma cidade mais verde, mais amiga, mais tranquila e tão receptiva onde as pessoas estabelecem, em um primeiro momento relações de confiança com você. É como se estivéssemos em outro Brasil, porque é muito diferente o modo de vida (de se relacionar com as pessoas) daqui comparado ao de Uberlândia". (Notas do diário de bordo de um dos professores que acompanharam a realização do projeto).

Aos poucos, percebemos que os alunos estrangeiros eram tomados pelo linguajar brasileiro: ao invés de se bloquearem para atitudes diferentes do normal aos seus parâmetros culturais, se abriam curiosamente para novas formas de interesse e relações com o normal da cultura do outro. Como produto dessa curiosidade, a Língua Portuguesa passou a emergir naturalmente desses sujeitos e produzir sentidos para eles. 


\section{Revista do SELL \\ v. $4, n^{\circ} .1$ \\ ISSN: $1983-3873$}

Percebemos como professores, que ao invés de utilizarem a uma comunicação pensada ${ }^{7}$, os estrangeiros, que estavam no Brasil há apenas três meses, começavam a se fluir nesses novos códigos ${ }^{8}$ e parâmetros de comunicação ${ }^{9}$.

No findar do projeto ficaram saudades, amizades, nostalgia e até mesmo planos por parte dos alunos para retornarem à cidade para visitarem as famílias que os acolheram. Juntamente com essas reflexões, o desejo de aprenderem a Língua Portuguesa (LP) aumentou. Ainda dentro do ônibus, de volta à cidade de Uberlândia, os alunos perguntaram quanto tempo ainda teriam de aula, e se novos projetos como estes estavam inclusos no curso. Finalizaram a viagem dizendo que o final de semana tinha sido incrível para o desenvolvimento de sua capacidade de produção e expressão oral em LP.

Os frutos colhidos da realização da primeira edição do projeto Brasil sem Fronteiras abrem leques para várias análises e pressupostos de construções teóricas acerca do ensino intercultural de PLE. Todavia, gostaríamos de deixar algumas reflexões sobre como a realização do projeto aprimorou a aprendizagem dos alunos estrangeiros após a sua realização.

Nas ultimas dez aulas que ainda nos restavam, os alunos passaram a ser mais frequentes. Além disso, desejavam aprender não mais a língua na sua forma descritiva ${ }^{10}$, mas o que era enunciado a partir de determinada estrutura em contexto específico, como podemos observar nas perguntas feitas pelos estrangeiros:

-Professor onde e de que forma eu uso "oil", "olá!", e "aí, tá beleza?"?

-Qual que é a diferença de "quanto custa" e "quanto é"? É que eu percebo que em determinadas vezes as pessoas usam "quanto custa" e em outras as pessoas usam "quanto é", como, por exemplo, ontem eu fui no mercado e escutei uma pessoa dizendo "quanto custa o açúcar?" e já na lanchonete aqui da faculdade as pessoas falam "quanto é o salgadinho?"

\footnotetext{
${ }^{7}$ Referimo-nos aos momentos em que, por exemplo, um sujeito torce o olho e desloca sinuosamente seus ombros, pescoço, braços e mediastinos procurando palavras na língua portuguesa para descrever, expressar, ou demonstrar algo ou um objeto.

${ }^{8}$ Novos códigos é colocado no sentido de novas linguagens expressas por meio dessa nova língua.

${ }^{9}$ Parâmetros de comunicação deve ser entendido como os diferentes discursos e efeitos discursivos que regem uma comunidade.

${ }^{10}$ A partir do entendimento de seus sistemas e normas.
} 


\title{
Revista do SELL
}

v. $4, n^{\circ} .1$

ISSN: $1983-3873$

\begin{abstract}
-Por que a gente fala "vou lá não" ao invés de falar o certo que é "não, eu não vou lá". Tem diferença entre um e outro? É que não vejo ninguém falar da forma que a gente aprendeu que é "não, não vou lá não".
\end{abstract}

(Recortes de diários reflexivos dos professores dos cursos de PLE da UFU).

Por fim, consideramos que a aprendizagem nessas aulas foi bastante acelerada em relação às aulas anteriores à realização do projeto Brasil sem Fronteiras. Além disso, a fluência dos alunos em LP se tornou progressiva e natural ao passo que o curso ia chegando ao fim. No final do curso pedimos para que os alunos fizessem um relato de experiência de estudar PLE no Brasil e de todos os participantes da primeira edição do projeto mencionaram a viagem à Patrocínio como sendo o lugar onde mais aprenderam LP durante o curso.

Ao mesmo tempo, os membros do Lions fizeram suas considerações sobre a oportunidade de desenvolver este tipo de projeto e de intercâmbio cultural. Segundo relato do presidente da associação, a possibilidade de contato com os estrangeiros foi um espaço muito rico para se repensar alguns clichês sobre os estrangeiros. Além disso, houve espaço para novas amizades, para conhecer a realidade presente no dia-a-dia, como por exemplo, a quantidade de pássaros que canta na rua ou a quantidade de insetos que passa despercebida.

Ainda sem conclusões definitivas em relação aos objetivos do projeto, apontamos que as intenções iniciais foram fortemente atingidas e que através de trocas de experiências pessoais, impressões e discussões entre os envolvidos no projeto o ensino de PLE atingiu um patamar de expressão de identidades individuais na construção de identidades coletivas. Observamos que o ambiente de ensino de PLE em contexto de imersão depende muito das práticas adotadas. Nesse sentido, é preciso considerar as diferenças socioculturais e linguísticas dos alunos; é importante ensinar o humano, o geográfico, o histórico, a cultura e a identidade de nosso povo brasileiro em toda sua diversidade; é, pois, fundamental, transformar a interação em momentos de afetividade singulares que modifiquem o processo de aquisição da língua-alvo. 


\section{Revista do SELL \\ v. $4, n^{\circ} .1$ \\ ISSN: $1983-3873$}

\section{Considerações finais}

Uma análise mais aprofundada do ensino e aprendizagem de PLE demonstra que a pluralidade linguística evidencia de um lado, um reconhecimento e uma legitimação da importância das relações interculturais em sala de aula de PLE, e de outro, a possibilidade de trabalho com conceitos transversais, tais como ética, inserção e integração sociais.

Uma reflexão sobre a natureza dos conteúdos interculturais deve ser incorporada à sala de aula de PLE, na medida em que essa diferenciação de conteúdos auxilia professores e alunos estrangeiros a interagirem na pluralidade linguística em contexto de tradições culturais brasileiras, fazendo da diversidade cultural componentes de uma identificação nacional. Além disso, os aspectos linguísticos são vivenciados nas próprias interações em contexto real, o que faz da imersão cultural um mecanismo de aprendizagem educativa mais completa, dinâmica e deliberadamente compatível com as experiências e os conhecimentos transmitidos e aprendidos.

A questão de possíveis conflitos e demandas culturais passa a ser um desafio positivo, porque é levada para uma discussão no grupo sobre o respeito a todas as formas culturais e a reciprocidade das trocas interativas que se realizam através da abertura à alteridade.

A interculturalidade se define, portanto, como esperávamos, através da relação entre as culturas, mas muito mais pela relação entre os indivíduos nas interações sociais em imersão cultural brasileira, o que nos leva a pensar na necessidade de um trabalho individualizado, progressivo e visando o sujeito em formação linguística e cultural.

Quaisquer que sejam os embates e/ou dificuldades no ensino e aprendizagem de PLE, nossa experiência com o projeto Brasil sem Fronteiras nos ensina, a cada novo grupo de estrangeiros que nos chega para o aprendizado da língua portuguesa, que é fundamental a tomada de consciência da multidimensionalidade e variação dos processos de integração linguístico-cultural que fazem parte do contexto específico do ensino de PLE. Só assim poderemos estabelecer programas que abarquem diferentes nacionalidades e diferentes culturas e que priorizem o sujeito em suas relações interculturais, interindividuais e intergrupais. 


\section{Referências}

ABDALLAH-PRETECEILLE, M; PORCHER, L. Éthique de la diversité et éducation. Paris:PUF, 1998.

AUGÉ, M. Non-lieux. Introduction à une anthropologie de la surmodernité. Paris : Le Seuil, 1992.

BALANDIER, G. Anthropo-logiques. Paris : Librairie générale française, 1974.

BARBIRATO, Rita C. Tarefas geradoras de insumo e qualidade interativa na construção do processo de aprender língua estrangeira em contexto inicial adverso. 2005. Tese (Doutorado em Linguística Aplicada) - Instituto de Estudos da Linguagem, Universidade Estadual de Campinas, Campinas, 2005.

BYRAM, M. Culture et education en langue étrangère. Paris: Hatier, 1992.

; NICHOLS, A.; STEVENS, D. "Introduction". In: M. BYRAM; A.

NICHOLS \& D. STEVENS (ed.). Developing Intercultural Competence in Practice. Clevedon: Multilingual Matters (1-8), 2001.

; ZARATE, G. "Definition, objectives and assessment of sociocultural competence". In M. BYRAM; G. ZARATE \& G. NEUNER (ed.), Sociocultural competence in language learning and teaching. Strasbourg: Concelho da Europa (7-43), 1997.

CANDAU, Vera Maria( Org.). Sociedade, Educação e Cultura(s): questões e propostas. Petrópolis, RJ: Vozes, 2002. 


\section{Revista do SELL}

v. $4, n^{\circ} .1$

ISSN: $1983-3873$

.Reinventar a Escola. Petrópolis, RJ: Vozes, 2000.

CANDELIER, M. L'introduction de l'Eveil aux Langues dans le curriculum. Graz, ECML, 2000.

Rapport concernant les objectifs (2001). Disponível em http://jaling.ecml.at/pdfdocs/evlang/evlang1.pdf. Acesso em 19 de abril de 2005.

COPE, B.; KALANTZIS, M. Multiliteracies: literacy learning and the design of social futures. London, 2000.

FORQUIN, Jean Claude. Escola e Cultura: as bases sociais e epistemológicas do conhecimento escolar. Porto Alegre: Artes Medicas Sul, 1993.

GEE, J. P. Situated Language and Learning. New York and London, 2004.

GOFFMAN, E. Les rites d'interaction. Paris, Ed. De Minuit, 1974.

MOITA LOPES, L. P. (1996) Oficina de Linguística Aplicada: a natureza social e educacional dos processos de ensino/aprendizagem de línguas. Campinas: Mercado das Letras.

OGAY, T. De la compétence à la dynamique interculturelles. Bern: Peter Lang, 2000.

LACAN, Jacques. O seminário, Livro 17: O avesso da psicanálise (1969 - 1970). Rio de Janeiro: Zahar, 1992.

LÉVI-STAUSS, C. Raça e História. In: Antropologia estrutural dois. 4a edição. Rio de Janeiro: Tempo Brasileiro, 1993. 


\section{Revista do SELL}

v. $4, n^{\circ} .1$

ISSN: $1983-3873$

LANKSHEAR, C. \& KNOBEL, M. New Literacies, Changing Knowledge and Classroom Learning. Open University Press. London and New York, 2003.

LOCK, J. Ensaio acerca do entendimento humano. Tradução de Anoar Aiex e E. Jacy Monteiro. $2^{a}$ ed., São Paulo: Ed. Abril Cultural, 1978.

Quadro Europeu Comum de Referência para as línguas. Aprendizagem, ensino, avaliação. Porto: Edições Asa, dez/2001 (1ª ed.).

PENNYCOOK, Alastair. Critical Applied Linguistics. In: DAVIES, Alan; ELDER, Catherine (Ed.). The Handbook of Applied Linguistics. Oxford: Blackwell Publishing, 2004. p. 782807.

SHEILS, J. (coord.) "Apprentissage et usage des langues dans le cadre européen". In Le Français dans le Monde, Recherches et Applications, 1998. Resumo disponível em http://www.fdlm.org/fle/ra/0798-ra.php. Acesso em 27 de janeiro de 2006.

TRIM, J. L. et al (2001). Quadro Europeu Comum de Referência para as Línguas Aprendizagem, ensino, avaliação. Porto: Edições Asa (tradução). ISBN 972-41-2746-X. 